\title{
A crescente preocupação com a integração de saberes através do currículo
}

\author{
Preoccupation with the integration of knowledge across \\ of the curriculum has increased
}

Emerson Bianchini Estivalete ${ }^{a}$

\section{Editor}

Maria Inês Côrte Vitoria PUCRS, RS, Brasil

\section{Editor Executivo}

Pricila Kohls dos Santos PUCRS, RS, Brasil

\section{Equipe Editorial}

Rosa Maria Rigo PUCRS, RS, Brasil

Carla Spagnolo

PUCRS, RS, Brasil

Martha Luci Sozo

PUCRS, RS, Brasil

Dirce Hechler Herbertz

PUCRS, RS, Brasil

\section{ISSN 2179-8435}

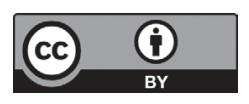

Este artigo está licenciado sob forma de uma licença Creative Commons Atribuição 4.0 Internacional, que permite uso irrestrito, distribuição e reprodução em qualquer meio, desde
seja corretamente citada http://creativecommons.org/licenses/by/4.0/deed.pt_BP
RESUMO: Partindo do pressuposto de que é possível acreditar em uma prática pedagógica que permita a real integração de saberes, o presente artigo busca elucidar o estado do conhecimento relativo à necessidade da constante busca dos processos educacionais envolvidos nesta integração. A partir da crença de que este é um ideal a ser perseguido, sobretudo no que tange às organizações curriculares, esse estudo pretende analisar não apenas de que forma, mas também em que contextos as questões em torno da organização do currículo integrado estão sendo abordadas em trabalhos científicos. A metodologia de construção do estado de conhecimento acerca da temática foi realizada com base no levantamento das publicações disponibilizadas no site da ANPEd, bem como no Banco de Teses da CAPES. O levantamento das pesquisas encontradas indica que, ao longo dos anos, vem aumentando o interesse da comunidade acadêmica pela temática da integração de saberes através do currículo, haja vista o número de trabalhos encontrados que propõe reflexões sobre o assunto.

Palavras-chave: educação; currículo; integração de saberes.

ABSTRACT: Assuming that it is possible to believe in a pedagogical practice that allows the integration of real knowledge, the present article seeks to elucidate the state of knowledge concerning the necessity of constant pursuit of educational processes involved in this integration. From the belief that this is an ideal to be pursued, especially in relation to curricular organizations, this study aims at examining not only how, but also the contexts in which issues surrounding the organization of the integrated curriculum are being addressed in scientific papers. The construction methodology of the state of knowledge about the theme was based on the survey of publications available in ANPEd site as well as in the Bank of CAPES thesis. The survey indicates that, over the years, the interest of the academic community in the topic of integration of knowledge across the curriculum has increased, given the number of studies found that propose reflections on the subject.

Keywords: education; curriculum; integration of knowledge.

a Licenciado em História. Especialista em História, Ensino e Pesquisa. Mestre e Doutorando em Educação pelo PPGEdu da
PUCRS. Professor Efetivo do Ensino Básico, Técnico e Tecnológico do Instituto Federal Catarinense - Campus Rio do Sul. 


\section{Introdução}

currículo pode ser entendido como um processo dinâmico que se constrói lentamente na sociedade, no enfrentamento dos conflitos e interações sociais. Nessa construção, o ontem e o hoje estão em constate confronto, provocando questionamentos na formulação do conhecimento a ser utilizado no presente e no futuro. Sendo assim, buscando uma conceituação mais ampla:

Frequentemente, acha-se que currículo significa um programa de estudos. Quando libertamos nossa imaginação da noção limitada de que um programa de estudos é uma série de livros-texto ou um resumo específico de tópicos a serem cobertos e de objetivos a serem atingidos, noções mais amplas e significativas emergem. Um currículo pode se tornar o programa de ação de uma vida. Ele pode significar os caminhos que nós seguimos e os caminhos que pretendemos seguir. Nesse sentido amplo, o currículo pode ser visto como a experiência de vida de uma pessoa (CONNELLY e CLANININ, 1988, apud McKERNAN, 2009, p. 31-32).

Dessa forma, o currículo passa a ser uma variável em constante transformação no processo de formulação dos conhecimentos, pois "é preciso reconhecer que a inclusão ou exclusão no currículo tem conexão com a inclusão ou exclusão na sociedade" (GOODSON, 1995, p. 10). "Em síntese, o currículo escrito nos proporciona um testemunho, uma fonte documental, um mapa de terreno sujeito a modificações, constitui também um dos melhores roteiros oficiais para estrutura institucionalizada da escolarização" (GOODSON, 1995, p. 21).

A partir disso, o currículo deve ser entendido como um elemento essencial pra o desempenho das atividades docentes: orienta o ensino, viabiliza a aprendizagem, organiza os conhecimentos a serem trabalhados no processo educativo, pois o desenvolvimento curricular é uma ação dinâmica e contínua composta por diferentes fases que se articulam entre si e devem ser norteadas pela busca de significado. Essas fases do currículo são definidas por Pacheco (2005) como: currículo prescrito - que são os planos curriculares, programas, listagem de conteúdos a serem vencidos, objetivos a serem alcançados, competências a serem construídas, atividades a serem executadas e avaliações a serem aplicadas, todo essa cabedal de operações pode ser definido como proposta formal adotada por uma estrutura organizacional escolar; currículo apresentado - são os mediadores curriculares (manuais, livros didáticos, textos, CDs, jogos, programas de áudio e vídeo, filmes, documentários, entre outros exemplos), em que os professores não trabalham diretamente com o prescrito; currículo programado - projeto político pedagógico definido em grupo; currículo planificado - currículo elaborado individualmente pelos professores; e, por último, e, talvez, o 
mais significativo, o currículo real - que também é definido por Sacristán (2000) como atividade de sala de aula ou, fora dela, que acontece no cotidiano de forma prática.

A partir dos estudos de Pacheco (2005) sobre as fases do currículo, foi possível entender que a concretização de uma integração curricular demanda uma prática pedagógica que seja uma expressão forte do diálogo entre todos os âmbitos curriculares apresentados, devendo-se cristalizar em realidade.

Ainda sobre a organização do conhecimento, é importante ressaltar que o currículo que se realiza por meio de uma prática pedagógica é resultado de uma série de influências convergentes e sucessivas, coerentes ou contraditórias, adquirindo, dessa forma, a característica de ser um objeto preparado num processo complexo, que se transforma e se constrói no mesmo. Por isso, exige ser analisado não como um objeto estático, mas como a expressão de um equilíbrio entre múltiplos compromissos. E, mais uma vez, essa condição é crucial tanto para compreender a prática escolar vigente como para tratar de mudá-la (SACRISTÁN, 2000).

Quando observamos o contexto diário das relações em sala de aula, é possível constatar uma preocupação, muitas vezes desmedida, por parte do professor, em valorizar os conteúdos específicos de sua respectiva área do conhecimento sem a devida atenção ao significado dessas contribuições para o preparo do discente no sentido da formação integral do ser humano que está inserido num mundo social. Essas práticas podem comprometer o interesse do aluno pela proposta de trabalho do professor, levando à apatia e à permanência em sala de aula ou em qualquer outro ambiente de aprendizagem pelo simples cumprimento de rotinas e protocolos que pouco agregam à significação das suas vivências escolares, podendo desencadear em desgastes desnecessários para todos os envolvidos nesse processo.

Diante de tais inquietudes é que o currículo pode ser organizado como um importante mecanismo de minimização desses efeitos, quando dimensionado numa perspectiva voltada para integração, justificando-se, portanto a relevância deste trabalho, cuja metodologia consiste no levantamento de estudos realizados na área no Banco de Teses da Capes e nos trabalhos apresentados na ANPEd.

\section{0 currículo na perspectiva da integração}

Encontramos em Santomé (1998) uma das maiores preocupações no que tange à organização curricular sob uma perspectiva integrada: a valorização das tomadas de decisões em conjunto, pelos professores, na escolha dos conteúdos culturais e na formulação de metodologias que possam ter real significado humano, além do técnico ou preparatório nas relações de ensino e aprendizagem.

Essa forma articulada de ensinar e aprender possibilita a humanização do conhecimento, de forma a tornálo mais significativo, pois o processo pedagógico é proveniente de ambientes concretos, nos quais as pessoas 
envolvidas aparecem como sujeitos participantes e com capacidade de intervir na sua própria história. Assim, pode-se operacionalizar currículo e trabalho como uma ação estratégica capaz de desvendar a realidade no sentido da sua compreensão, potencializando formas de autonomia e superação.

Outra argumentação de Santomé (1998) em defesa dessa modalidade curricular se sustenta nas possibilidades oferecidas por esse novo método de trabalhar a educação de forma mais globalizada e interdisciplinar, estimulando a criação de mecanismos para integrar os conhecimentos das diversas áreas das ciências humanas e das ciências naturais.

Contudo, há necessidade de tentarmos clarificar o significado de integrar que, para Ciavatta (2005), "é tornar íntegro, tornar inteiro". Na ideia da autora, isso acontece quando o processo educacional alcança significado para o aluno de modo a "enfocar o trabalho como princípio educativo"".

A ideia de formação integrada sugere superar o ser humano dividido historicamente pela separação social do trabalho entre ação de executar e a ação de pensar, dirigir ou planejar. Trata-se de superar a redução da preparação para o trabalho no seu aspecto operacional, simplificado, escoimado dos conhecimentos que estão na sua gênese científico-tecnológica e na sua apropriação histórico-social. Como formação humana, o que se busca é garantir ao adolescente, ao jovem e ao adulto trabalhador o direito a uma formação completa para a leitura do mundo e para atuação como cidadão pertencente a um país, integrado dignamente na sociedade política (CIAVATTA, 2005).

Vale lembrar que Ciavatta (2005) corrobora com Saviani (1994), ao afirmar que o trabalho foi, é e continuará sendo o princípio educativo do sistema de ensino em seu conjunto, pois a preocupação com o trabalho aparece nas bases de formação da escola primária, no seu desenvolvimento e diversificação e tende a determinar, no contexto das tecnologias avançadas, a sua unificação (SAVIANI, 1994).

Desse modo, a retomada dessas discussões tem origem nas reflexões oriundas do declínio do modelo nacionaldesenvolvimentista que atrelava a educação brasileira às necessidades do mercado de trabalho. Diante das novas demandas surgidas com o processo de globalização, ficou superada a ideia de preparar para o mercado de trabalho, dada a sua instabilidade, dever-se-ia, então, preparar para a "vida". Esse pensamento foi uma das importantes âncoras que pautou a redação da atual Lei de Diretrizes e Bases da Educação no Brasil.

\footnotetext{
1 Trabalho como Princípio Educativo. Alinhados a Saviani (1989), podemos considerar o trabalho como princípio educativo em três sentidos diversos, mas articulados entre si. Num primeiro sentido, o trabalho é princípio educativo, na medida em que determina, pelo grau de desenvolvimento social atingido historicamente, o modo de ser da educação em seu conjunto. Nesse sentido, aos modos de produção correspondem modos distintos de educar com uma correspondente forma dominante de educação. E um segundo sentido, o trabalho é princípio educativo, na medida em que coloca exigências específicas que o processo educativo deve preencher, em vista da participação direta dos membros da sociedade no trabalho socialmente produtivo. Finalmente, o trabalho é princípio educativo num terceiro sentido, à medida que determina a educação como uma modalidade específica e diferenciada de trabalho: o trabalho pedagógico (SAVIANI, 1989, p. 1-2).
} 
Ao buscarmos uma retomada histórica das ideias até aqui abordadas, necessitamos entender o contexto da Revolução Russa e nele as concepções de Pistrak (2000), que via a educação como uma poderosa ferramenta capaz de fomentar mudanças na sociedade, sendo a formação integral um importante caminho de operacionalização desse ideal, na tentativa de conceber novos princípios formativos que guardassem em si significados do e para o mundo. Daí pode-se perceber a necessidade do desenvolvimento de uma educação para além dos conteúdos escolares, explorando e problematizando o passado com as devidas mediações dialéticas do presente e, junto a elas, a construção de uma perspectiva de futuro. Nessa direção:

O trabalho na escola, enquanto base da educação deve estar ligado ao trabalho social, à produção real, a uma atividade concreta socialmente útil, sem o que perderia seu valor essencial, seu aspecto social, reduzindo-se, de um lado, à aquisição de algumas normas técnicas, e, de outro, a procedimentos metodológicos capazes de ilustrar este ou aquele detalhe de um curso sistemático. Assim, o trabalho se tornaria anêmico, perderia sua base ideológica (PISTRAK, 2000, p. 38).

De acordo com Pistrak (2000), a articulação entre o trabalho e a educação é condição fundamental para os processos de formação humana. Nesta perspectiva, a relação entre teoria e prática são pressupostos entendidos como pilares de sustentação para a formação do homem integral. O excerto a seguir é exemplar nesse sentido:

Conferimos uma enorme importância à criação técnica. Toda a criação, técnica, científica, artística é aptidão para combinar subconscientemente os elementos constitutivos que contribuem para a produção do objeto que se quer criar, e aptidão para escolher instintivamente, numa série de combinações, aquelas que são as melhores. Qualquer homem possui tais aptidões em maior ou menor grau: é preciso que a escola a desenvolva para todos os meios à sua disposição, e este é o objetivo dos novos métodos pedagógicos baseados na atividade de uma investigação do aluno (PISTRAK, 2000, p. 62).

Para Pistrak (2000), a fábrica era um centro complexo de relações sociais, sendo de fundamental importância a atenção da escola na formação dos alunos para essa questão. As crianças deveriam desenvolver a sua criatividade, estudando ao lado dos operários, como aprendizes, colaborando com a produção e, ao mesmo tempo, conhecendo a fábrica em todas as suas partes, condição fundamental para a percepção de trabalho numa perspectiva científica e, acima de tudo, formadora. A partir das contribuições de Pistrak (2000), muitas outras demandas se apresentarão no processo de formação pelo trabalho. 
De acordo com Ramos (2005), a função da escola estaria em proporcionar aos educandos o desenvolvimento de competências genéricas e flexíveis, adaptáveis à instabilidade da vida e não mais o acesso aos conhecimentos sistematizados.

Ainda nos esclarece Ramos (2005) que:

A escola e os sistemas de ensino precisam ter uma visão crítica do mercado de trabalho e construir o processo formativo no qual, ao tempo em que proporcionam acesso aos conhecimentos, contribuam para que o sujeito se insira no mundo do trabalho e também questione a lógica desse mesmo mercado (RAMOS, 2008, p. 28).

Nessa compreensão, o currículo integrado precisa ter como objetivo o aproveitamento e a utilização das necessidades e dos interesses dos discentes no processo pedagógico, por meio de programas democráticos voltados para soluções no sentido de enfrentar os problemas do cotidiano de dentro ou de fora das instituições educativas.

Frigotto (2005), ao discutir a relevância da articulação entre o trabalho, a cultura e o conhecimento científico, escreve:

O ensino médio, concebido como educação básica e articulado ao mundo do trabalho, da cultura e da ciência, passa constituir-se em direito social e subjetivo e, portanto, vinculado a todas as esferas e dimensões da vida. Trata-se de uma base para o entendimento crítico de como funciona e se constitui a sociedade humana em suas relações sociais e como funciona o mundo da natureza, da qual fazemos parte. Dominar no mais elevado nível de conhecimento estes dois âmbitos é condição prévia para construir sujeitos emancipados, criativos e leitores críticos da realidade onde vivem e com condições de agir sobre ela. Este domínio também é condição prévia para compreender e poder atuar com novas bases técnico-científicas do processo produtivo (FRIGOTO, 2005, p. 76).

Portanto, a implementação do currículo integrado alinhado às concepções teóricas referenciadas nesta investigação, torna-se uma modalidade de organização curricular que possibilita a superação da fragmentação do ensino e do conhecimento, na perspectiva de evitar a reprodução de ideologias do estado regulador e representante do pensamento hegemônico, aliada à coibição do processo de alienação do indivíduo e, consequentemente, de superar as fronteiras invisíveis das disciplinas em prol de conhecimentos culturais e interdisciplinares essenciais na formação dos cidadãos. 
Nessa ótica, novos desafios são postos, quando, na sala de aula ou em quaisquer outros espaços que se configure como cenário de encontro desses atores, eles precisam construir em conjunto um projeto de aprendizagem.

\section{A preocupação com a integração de saberes: um movimento crescente}

Ao longo de sua trajetória, a compreensão do que vem a ser o currículo vem sofrendo interferências políticas, econômicas, sociais e culturais, sendo, em muitos casos, reduzido à "grade curricular", aqui entendida como uma listagem de disciplinas isoladas em seus campos de conhecimento específicos.

O currículo, portanto, apresenta-se como um instrumento que faz o cruzamento das inúmeras áreas do conhecimento com diferentes práticas pedagógicas, configurando-se, assim, no principal eixo de orientação dentro do processo educacional como resultado da interação entre os sujeitos da ação pedagógica.

Nessa perspectiva e com base na sua importância nos processos educacionais, este artigo busca analisar de que forma e em quais contextos as questões que envolvem a organização do currículo integrado estão sendo abordadas pela comunidade acadêmica em trabalhos científicos.

Considerando-se que, para Bardin (2009, p. 23), "a análise pode efetuar-se numa amostra desde que o material a isso se preste" e [...] "diz-se rigorosa se [...] for uma parte representativa do universo inicial", optou-se por privilegiar o site da ANPEd, mais especificamente o GT 12, e o Banco de Teses da CAPES, entendendo que por serem órgãos reconhecidos junto à comunidade acadêmica e por divulgarem grande parte da produção intelectual do campo em questão, atendem perfeitamente ao que preconiza a autora acima citada. Ainda, segundo Bardin (2009), "nem todo o material de análise é susceptível de dar lugar a uma amostragem, e, nesse caso, mais vale abstermo-nos e reduzir o próprio universo (e, portanto, o alcance da análise) se este for demasiado importante" (ibid., p. 123), razão pela qual, a busca foi restringida aos últimos cinco anos.

Valendo-se da metodologia "tipo estado de conhecimento", o presente estudo busca quantificar e analisar a produção científica através de reflexões que abordem aspectos relacionados à integração dos componentes e elementos curriculares, em especial no ensino médio profissionalizante de nível técnico.

O site da ANPEd é organizado de acordo com suas reuniões anuais e conta atualmente com 24 GTs que produzem trabalhos científicos em diferentes áreas da educação. Na proposta aqui apresentada, coube a análise do GT 12 Currículo, no qual foi verificada, nos últimos cinco anos, a apresentação de somente três trabalhos: dois em 2009, na 32a Reunião Anual, tendo como categorias o ensino básico propedêutico e o ensino básico de nível técnico, e um em 2011. 
Luz (UFPI, 2009) objetivou analisar e avaliar as contribuições do método de projeto de trabalho na organização e articulação do conhecimento entre as diferentes disciplinas que compõem o curso técnico em agropecuária, concomitante ao ensino médio do Colégio Agrícola de Floriano, sob a ótica do pensamento complexo e da transdisciplinaridade.

Costa (UFF, 2009) objetivou discutir os discursos circulantes na política de currículo do PROEJA - Programa de Integração da Educação Profissional com o Ensino Médio, na modalidade Educação de Jovens e Adultos. Considerando-se que essa política para a educação profissional privilegia o público da EJA, de forma a assegurar-lhe ingresso em cursos técnicos integrados ao ensino médio, em escolas públicas federais, e que, a despeito desse direito assegurado, constata-se, hoje, um elevado índice de evasão de alunos, é possível afirmar que esses discursos não podem ser compreendidos fora das relações materiais que os constituem.

Em 2011, na 34a Reunião Anual, foi apresentado outro trabalho que também atendia à categoria do ensino básico propedêutico. Felício (PUC-Rio, 2011) analisou a integração curricular na perspectiva de uma parceria interinstitucional, em um contexto educativo formado por duas instituições - uma escola pública e uma organização sem fins lucrativos - com o intuito de identificar os desafios de tal integração para o desenvolvimento da Educação em Tempo Integral. O contexto investigado, a partir de uma perspectiva qualitativa, atende educandos de uma comunidade instituída por um processo de desfavelização.

Ao acessar o site da Capes, clica-se em serviços no 'menu' vertical e depois em banco de teses, aparecerá uma 'janela' com sistema de filtros, no qual foram utilizadas as palavras ‘currículo integrado' para efetuar as buscas numa delimitação temporal, envolvendo os últimos dezesseis anos. O número dezesseis se deve ao fato de se ter efetuado a busca até que zerasse a quantidade de produções. De acordo com o Quadro 1, devido à grande quantidade de trabalhos encontrados - um total de 131 - foi possível verificar que houve um crescimento considerável na produção de trabalhos que enfocam o tema 'currículo integrado', principalmente nos últimos cinco anos. Dessa forma, identifica-se um movimento que aponta para a valorização das temáticas pertinentes a essa proposta de organização curricular no âmbito da comunidade acadêmica.

Vale destacar, ainda, que até o momento da busca, o site da CAPES não dispunha de todos os trabalhos feitos em 2013 para consulta. Desse modo, o recorte temporal se deu até 2012 e essa prática estendeu-se também para o site da ANPEd já que ambos foram avaliados de forma conjunta com objetivo de garantir maior amplitude a pesquisa. 
Quadro 1. Teses ou dissertações sobre currículo integrado - CAPES, 1997-2012.

\begin{tabular}{|l|l|c|}
\hline & Ano & Quantidade de trabalhos encontrados \\
\hline 16 & 1997 & 01 \\
\hline 15 & 1998 & 03 \\
\hline 14 & 1999 & 03 \\
\hline 13 & 2000 & 01 \\
\hline 12 & 2001 & 06 \\
\hline 11 & 2002 & 02 \\
\hline 10 & 2003 & 03 \\
\hline 09 & 2004 & 06 \\
\hline 08 & 2005 & 02 \\
\hline 07 & 2006 & 06 \\
\hline 06 & 2007 & 10 \\
\hline 05 & 2008 & 25 \\
\hline 04 & 2009 & 21 \\
\hline 03 & 2010 & 18 \\
\hline 02 & 2011 & 24 \\
\hline 01 & 2012 & 131 \\
\hline
\end{tabular}

Fonte: <http://www.capes.gov.br/servicos/banco-de-teses>.

Diferente do Quadro 1, que tinha como proposta quantificar o crescimento do número de trabalhos sem uma preocupação definida com a temporalidade, o Quadro 2 está definido de modo a contemplar os últimos cinco anos. Dessa forma, dos 131 trabalhos analisados inicialmente, 98 pertencem ao recorte temporal de 2008 a 2012, enquanto nos 11 anos anteriores identificaram-se somente 33 trabalhos. A partir de um foco no período de maior relevância, foram estabelecidas algumas categorias, conforme Quadro 2: 
Quadro 2. Categorias de análise de Teses ou Dissertações sobre currículo integrado - CAPES, 2008/2012.

\begin{tabular}{|l|l|c|c|c|c|c|c|}
\hline \multicolumn{1}{|c|}{ Categoria } & $\mathbf{2 0 0 8}$ & $\mathbf{2 0 0 9}$ & $\mathbf{2 0 1 0}$ & $\mathbf{2 0 1 1}$ & $\mathbf{2 0 1 2}$ & Total \\
\hline 01 & Ensino Médio Profissionalizante & 02 & 03 & 07 & 06 & 07 & 25 \\
\hline 02 & Educação Superior & 04 & 11 & 01 & 02 & 07 & 25 \\
\hline 03 & EJA/PROEJA & 01 & 02 & 07 & 05 & 04 & 19 \\
\hline 04 & Componente Curricular & 02 & 03 & 03 & 02 & 04 & 14 \\
\hline 05 & Formação de Professores & 01 & 02 & - & 01 & 01 & 05 \\
\hline 06 & Políticas Públicas & - & 01 & 01 & - & - & 02 \\
\hline 07 & Juventude & - & - & 01 & - & - & 01 \\
\hline 08 & Estado do Conhecimento & - & - & - & 01 & - & 01 \\
\hline 09 & Família & - & - & - & - & 01 & 01 \\
\hline 10 & Feiras & - & - & - & - & 01 & 01 \\
\hline 11 & Educação Infantil & - & 01 & - & - & - & 01 \\
\hline 12 & Avaliação & - & 01 & - & - & - & 01 \\
\hline 13 & Cooperativas & - & - & 01 & - & - & 01 \\
\hline 14 & Projeto Social & - & - & 01 & - & - & 01 \\
\hline
\end{tabular}

Fonte: <http://www.capes.gov.br/servicos/banco-de-teses>.

Ao analisar as informações contidas no Quadro 2, é possível observarque duas categorias despontam em relação às demais. A primeira delas trata do currículo integrado em âmbito do ensino médio profissionalizante. Em sua grande maioria, os trabalhos tratam acerca da articulação entre os conhecimentos vinculados aos componentes do ensino básico e os conhecimentos vinculados à formação técnica de nível médio. A segunda, por sua vez, tem como destaque a produção que evidencia demandas no ensino superior, em especial as áreas da saúde cujo relevo se dá na enfermagem.

Dessa forma, novamente ratifica-se o interesse crescente da comunidade acadêmica pela produção de trabalhos que proponham reflexões acerca da integração de saberes através do currículo, numa tentativa de garantir maior significado ao que se ensina. 
Retomando a produção de trabalhos sobre currículo na perspectiva integrada no GT 12 da ANPEd, é possível perceber um certo 'silêncio' que contraria a lógica de produção no Banco de Teses da Capes, sobre o qual são necessárias algumas discussões relevantes no que tange à proposta do trabalho.

A investigação demostrou a possibilidade de aproximar profissionais de diferentes áreas através do ensino, pois, como já colocado, os docentes da área da saúde também despontaram em produção de trabalhos que contemplam o viés da integração dos conhecimentos no sentido de fortalecer a aprendizagem dos conteúdos propostos pelo currículo oficial.

Aliado a isso, um paradoxo: constatou-se que os profissionais cuja formação se deu em especial na área da saúde, juntamente com outros profissionais não licenciados que se fazem representar no processo educativo formal nos cursos profissionalizantes, manifestaram (através da produção expressiva de trabalhos) a grande preocupação com o significado da aprendizagem. Cabe ressaltar, portanto, a necessidade de colaboração e estímulo contínuo dos educadores, a fim de que todos os envolvidos nos diferentes processos de formação possam se auxiliar reciprocamente, no sentido não só da construção de bons profissionais, mas também de bons cidadãos preparados para a vida em toda a sua plenitude.

\section{Para não concluir ...}

A proposta deste trabalho é potencializar as discussões acerca da organização do currículo de modo que se consiga, através da reflexão e do trabalho conjunto,conferir-lhe maior significado. Para Veiga (2003), seu planejamento deve priorizar a superação do conflito entre os diversos conhecimentos, diminuindo os efeitos fragmentários da divisão social e técnica do trabalho. Na esteira disso, Ciavatta (2005) argumenta que o currículo deveser organizado pelo viés da interdisciplinaridade, valorizando, assim, o processo de integração.

Santomé (1998) nos ensina que a interdisciplinaridade é uma ação pedagógica que tem como meta a construção de uma aprendizagem global, a visão do todo pelas partes, viabilizando a abertura das fronteiras do conhecimento e das disciplinas.

Complementando esse posicionamento, Gadotti e Barcelos (1993, p. 31) afirmam que "[...] a interdisciplinaridade está no âmago de cada disciplina. As disciplinas não são fatias do conhecimento, mas a realização de unidade do saber nas particularidades de cada uma". Para que se consiga entender a projeção desses conceitos, na prática, é importante que haja encontros para discussões e, partindo delas, reflexões acerca do entendimento de como essa interdisciplinaridade, intrínseca em cada disciplina pode ser fortalecida gerando repercussões positivas para o processo de ensino e aprendizagem. 
O estudo demonstra que há um reconhecimento crescente junto à comunidade acadêmica acerca da importância de valorizarmos o saber das diferentes áreas do conhecimento de forma integrada, contudo, para que isso possa se concretizar torna-se indispensável a predisposição dos professores em se envolverem no processo,já que a valorização da coletividade é um importante caminho para a construção de um senso de pertencimento para o atendimento as demandas dessa proposta de trabalho, pois a interdisciplinaridade e a integração curricular requerem uma forte articulação entre teoria e prática, aliada a uma boa formação pedagógica.

Por todo o exposto, observamos queatravés da produção acadêmica podemos estimular o comprometimento individual do educador com o borramento de fronteiras entre as diferentes áreas do saber e, com isso, auxiliar na desconstrução do isolamento do componente curricular, atribuindo-lhe maior significado no coletivo, de modo que possa fortalecer sua representação no processo de formação do indivíduo para o devir e, como consequência, atender de forma mais profícua a própria Lei de Diretrizes e Bases da Educação Nacional, LDBEN/96, que alerta sobre o compromisso da educação com o mundo do trabalho e com a prática social.

\section{Referências}

BARDIN, Laurence. Análise de conteúdo. Lisboa: Edições 70, 2009.

BRASIL, Lei de Diretrizes e Bases da Educação Nacional no 9394/96, de 20 de dez de 1996. Disponível em: <http://www4.planalto. gov.br/legislação>.

CIAVATTA, Maria. A Formação integrada: a escola e o trabalho como lugares de memória e de identidade. In: FRIGOTTO, Gaudêncio; CIAVATTA, Maria; RAMOS, Marise (Org.). Ensino Médio Integrado: concepções e contradições. São Paulo: Cortez, 2005.

FRIGOTO, Gaudêncio. Concepções e Mudanças no Mundo do Trabalho e no Ensino Médio. In: FRIGOTTO, Gaudêncio; CIAVATTA, Maria; RAMOS, Marise (Org.). Ensino Médio Integrado: concepções e contradições. São Paulo: Cortez, 2005.

GADOTTI, Moacir; BARCELOS, Eronita Silva. Construindo a escola Cidadã no Paraná. Brasília: MEC, 1993. (Cadernos de Educação Básica).

GOODSON, Ivor F. Currículo: teoria e história. 7. ed. Petrópolis (RJ): Vozes, 1995.

MCKERNAN, James. Currículo e imaginação: teoria do processo, pedagogia e pesquisa-ação. Trad. Gisele Klein. Porto Alegre: Artmed, 2009.

PACHECO, José Augusto. Escritos curriculares. São Paulo: Cortez, 2005.

PISTRAK, Moisey Mikhaylovic. Fundamentos da escola do trabalho. São Paulo: Expressão Popular, 2000.

RAMOS, Marise Nogueira. Possibilidades e desafios na organização do currículo integrado. In: FRIGOTTO, Gaudêncio; CIAVATTA, Maria; RAMOS, Marise (Org.). Ensino Médio Integrado: concepções e contradições. São Paulo: Cortez, 2005.

Educação Por Escrito, Porto Alegre, v. 7, n. 1, p. 34-46, jan.-jun. 2016 
SACRISTÁN, J. Gimeno. O currículo: uma reflexão sobre a prática. Trad. Ernani F. da F. Rosa. 3. ed. Porto Alegre: Artmed, 2000.

SANTOMÉ, Jurjo Torres. Globalização e interdisciplinaridade: o currículo integrado. Trad. Cláudia Shiling. Porto Alegre: Artes Médicas Sul, 1998.

SAVIANI, Dermeval. Sobre a concepçãodepolitecnia. Rio de Janeiro: EPSJV Fiocruz, 1989.

VEIGA, Ilma Passos Alencastro. Projeto político-pedagógico da Escola: uma construção possível. Campinas: Papirus, 2003.

Recebido em: setembro/2014

Aceito em: julho/2015

\section{Endereço para correspondência:}

Emerson Bianchini Estivalete

Rua Justina Debarba Ledra, 875 - Bairro Santana

Rio do Sul, SC, Brasil

<emersonestivalete@gmail.com> 